\title{
Does the economic recession influence the incidence of pertussis in a cosmopolitan European city?
}

Sílvia Brugueras ${ }^{1,2,3^{*}}$ D, Cristina Rius ${ }^{1,2,3}$, Joan-Pau Millet ${ }^{1,2,4}$, Martí Casals ${ }^{5}$, Joan A. Caylà ${ }^{1,4}$ and Barcelona Pertussis Working Group

\begin{abstract}
Background: In the last few years, pertussis has re-emerged worldwide. The aim of this article is to study how the incidence of the disease has evolved in Barcelona city over a 16-year period, and determine which factors are associated with the evolution of the disease. We discuss the causes of the observed changes considering different possibilities such as vaccination coverage, vaccine effectiveness, increased surveillance or the effect of the current economic recession.

Methods: We performed a cross-sectional, observational, population-based descriptive study using data for the 2000-2015 period from the notifiable diseases register maintained by Barcelona Public Health Agency. We used Poisson regression to compute adjusted odds ratios (aOR) and their corresponding 95\% confidence intervals (Cl).

Results: A total of 1791 cases were registered. The incidence of the disease increased throughout the city from 2011 onwards. While children under 1 year of age had the highest-incidence and were the most at risk (aOR=27. $18, \mathrm{Cl}: 23.51-31.44)$, we found that the age of affected children was higher in the last years. Incidence proportion (PRR) was lower among foreign-born children than native children (PRR $=0.43 \mathrm{Cl}: 0.32-0.58$ ). In the whole-cell vaccine period (2000-2004), the percentage of cases under 1 year of age who received the vaccine was lower than in 2005-2015 when the acellular vaccine was used $(p=0.01)$, suggesting a lower efficacy of the acellular vaccine. However, vaccination coverage in children under 6 years remained high ( 90\%), and there were no significant year-to-year variations $(p=0.757)$. Moreover, there did not appear to be any significant restrictions in medical care. According to the index of disposable household income (DHI), pertussis incidence increased from 2011 onwards in all neighbourhoods and remained higher in those with lower DHI.
\end{abstract}

Conclusions: The noteworthy increase in pertussis incidence does not seem to be due to the economic recession, but to other factors here described.

Keywords: Bordetella pertussis, Cities, Economic recession, Epidemiology, Pertussis vaccine, Whooping cough

\section{Background}

Pertussis is an infectious respiratory disease caused by the Gram-negative Bordetella pertussis bacterium. Clinical symptoms include paroxysmal cough and inspiratory stridor, which may be followed by periods of apnea [1]. Although it is more common and is associated with more

\footnotetext{
* Correspondence: silviabruguerastorrella@gmail.com

'Servei d'epidemiologia, Agència de Salut Pública de Barcelona, Barcelona, Spain

${ }^{2}$ Centro de Investigación Biomédica en Red de Epidemiología y Salud Pública (CIBERESP), Barcelona, Spain

Full list of author information is available at the end of the article
}

complication in children, it may occur in all age groups and there has been an increase in the age of detected cases of pertussis [1]. Adults suffer from less severe symptoms that are more difficult to diagnose, which results in increased risk of transmission within the family [2].

Pertussis is a Notifiable Disease (ND) that continues to be a public health issue worldwide despite broad vaccination coverage [3-5]. Globally, data from the European Centre for Disease Prevention and Control (ECDC) show an increase in the incidence of pertussis in the European Union (EU) from 2011 onwards. Several

(c) The Author(s). 2019 Open Access This article is distributed under the terms of the Creative Commons Attribution 4.0 International License (http://creativecommons.org/licenses/by/4.0/), which permits unrestricted use, distribution, and reproduction in any medium, provided you give appropriate credit to the original author(s) and the source, provide a link to the Creative Commons license, and indicate if changes were made. The Creative Commons Public Domain Dedication waiver (http://creativecommons.org/publicdomain/zero/1.0/) applies to the data made available in this article, unless otherwise stated. 
countries, including Spain, The Netherlands, Denmark, Belgium, Ireland and the United Kingdom (UK) witnessed an increase in incidence from 2011 onwards, while that in Italy and Greece has remain generally stable $[1,6,7]$. Non-European countries with broad vaccination coverage, such as the United States (US), Australia and Israel have also witnessed a re-emergence of pertussis. However, several reports indicate that this is not a global re-emergence of the disease [3, 7-9].

In several countries, such as the US, Mexico, Croatia and Thailand, economic recessions have been shown to have an impact on communicable diseases because of the subsequent increase in inequalities between different population groups. Disease transmission may increase because of increased contact, poorer living conditions, poorer access to treatment, and lower treatment adherence. In addition, public funding allocated to preventing such diseases may be affected by austerity policies, resulting in decreased care for individuals in greatest need $[10,11]$. The current global economic recession started in 2008 , and as yet there are no data on trends in the pertussis incidence in the context of this economic recession at local level.

In the current study we: (i) describe the clinical and epidemiological features of pertussis in Barcelona between 2000 and 2015; (ii) analyse how the incidence of the disease evolved; (iii) evaluate the effect of the type of vaccine administered among children under 1 year old (whole-cell vs acellular vaccine); (iiii) determine which factors are associated with the increasing incidence in the city between 2000 and 2015 considering variables such as the gender, the age group, the socioeconomic status and the period. Through a description of the disease over the years, we discuss the potential etiological factors of this increase and analyse whether the economic recession had an impact in pertussis incidence.

\section{Methods}

\section{Design}

Cross-sectional, observational, population-based descriptive study.

\section{Population}

Pertussis cases of Barcelona notified by clinicians, microbiologists and public health nurses to the register of notifiable diseases (ND register) maintained by the Epidemiology Service of the Barcelona Public Health Agency (BPHA), Spain, between January 1st, 2000 and December 31st, 2015. The population of Barcelona during the period was between 1.503.884 inhabitants in 2000 and 1.609 .550 in 2015 [12].

\section{Pertussis-related activities}

Pertussis cases are reported to the BPHA, which carries out the follow-up of the cases and conducts the study of contacts. The study of contacts consists in reviewing the vaccination status of the contacts and adapting it to the immunisation schedule and administering prophylaxis to all contacts, following the pertussis guidelines of the from the health department of Catalonia. In order to know the vaccination status of the whole population there is a record in the Shared Medical History of Catalonia (HCCC) of the total population that receives healthcare in Catalonia. The immunization coverage in Barcelona has remained high. During the 2010-2015 period, primary vaccination among 1 year old children was between 90 and $95 \%$ and the complete vaccine coverage in young people aged 17 years was $68-77 \%$ (source: Sistema d'Informació dels Serveis d'Atenció Primària SISAP, Institut Català de la Salut). The immunisation program has remained the same during the study period except for the replacement of the whole-cell vaccine for the acellular vaccine. From 2004 to 2005 the acellular vaccine was administered at all doses.

\section{Case definition}

Cases with a clinical suspicion of pertussis were those in which the typical clinical coughing symptoms were present for two weeks or longer, followed by one or several of the following symptoms: paroxysmal coughing, inspiratory stridor, vomit or apnea after coughing. No laboratory confirmation was available in such cases. A pertussis case was considered confirmed in patients with confirmed infection by $B$. pertussis using laboratory diagnostic tests, based on culture or Polymerase Chain Reaction (PCR). Confirmed cases also included patients who showed typical clinical symptoms and were epidemiologically related to any other case that had already been confirmed with laboratory tests. Both suspected cases and confirmed cases were considered pertussis cases for the purposes of the current study [13].

\section{Variables}

Socio-demographic variables included gender, age (divided in 4 groups according to the most common distribution of pertussis: < 1, 1-14, 15-29 and > 30 years old), country of origin (native, foreign-born) and socio-economic status (divided in 5 groups, see below). Epidemiological variables were the following: conclusion (confirmed case, suspected case), association with other cases (sporadic, associated) and contact tracing. Clinical variables included symptoms (cough, paroxysmal coughing, inspiratory stridor, vomiting after coughing, apnoea, fever, pneumonia and convulsions), evolution (curation, death), vaccination, proper vaccination, laboratory diagnosis (culture, PCR) and hospital admission.

Vaccination variables included the number vaccinated cases (1 or more doses), non-vaccinated cases and cases of unknown vaccination status. 
Proper vaccination status was defined as follows: people older than 2 years who had been given at least 4 vaccination doses; toddlers between 1 and 2 years of age who had been given at least 3 doses (proper primary vaccination), babies between 6 months and 1 year who had received at least 2 doses; babies between 3 and 6 months who had received at least 1 vaccination doses; all babies less than 3 months old [14]. The age groups used to analyse the vaccination variables were under 1 year old and under 6 years old.

To determine the socio-economic status of people suffering from pertussis, we classified neighbourhoods of residence -assigned according to the mailing address provided in the survey- according to the index of disposable household income (DHI). The DHI had the following categories: very high (>159), high (126-159), average (100-125), average-low (between 79 and 99), and low (below 79). The DHI was constructed by analysing the following 5 indicators [15]:

1. Percentage of people with a degree: number of residents aged $\geq 25$ years with a diploma, degree, or Ph.D. as a percentage of the total number of residents aged $\geq 25$ years

2. Unemployment rate: number of unemployed people as a proportion of the total workforce

3. Private cars/1000 residents: number of cars owned by neighbourhood residents*1000/total residents

4. New high-power cars/total of new cars: number of cars less than two years old with more than 16 fiscal horsepower/the total number of cars under two years old (owned by residents; fiscal horsepower refers to a tax on high-powered vehicles in Spain)

5. Price of second-hand housing: Unit price of secondhand homes in euros.

Using the year variable, we created a new variable, period, to divide the years of the study into three periods: 2000-2004, 2005-2010 (after vaccines were changed from whole-cell vaccines to acellular vaccines) and 2011-2015 (years of the epidemic). We also created a new variable to identify the pre-recession (2000-2008) and recession periods (2009-2015).

To evaluate the effect of the type of vaccine administered, we created a vaccination period variable and classified children under 1 year old in either the whole-cell vaccine period (2000-2004) or the acellular vaccine period (2005-2015), depending on the type of vaccine received.

We also considered incidence differences between children under 15 years old foreign-born and natives.

\section{Information sources}

Data were obtained from epidemiological surveys carried out by the Barcelona ND register. We used Barcelona city's local census to obtain data on the total population in the city each year, distributed according to gender, age group, and neighbourhood. The DHI was constructed by Barcelona City Council Statistics Department [15].

\section{Statistical methods}

We conducted a descriptive study of pertussis cases in Barcelona between 2000 and 2015, and calculated the annual incidence proportion of pertussis in the city overall, and according to sex, age group, DHI, and country of origin (number of cases per 100,000 residents). Incidence proportions were obtained by dividing the number of notified pertussis cases by the total population in each group. We also computed the incidence trend line that best fit the observed data. Incidence proportion rate ratio (PRR) in foreign-born under 15 years old versus natives was calculated.

As subanalysis, we compared vaccination coverage before and after the economic recession. We also determined the proportion of cases among children under 1 year old who had received either whole-cell or acellular vaccination, and used univariate analysis to evaluate potential significant differences.

To study the possible risk factors for the incidence of notified pertussis cases at the multivariate level, a generalized linear model (GLM) was used assuming the frequency of the cases followed a Poisson distribution. We performed this analysis using aggregated data (with incidence as the dependent variable) to determine the effect of the following variables on the incidence trend: gender, age group, DHI, and period. The model was adjusted for the variables gender, age group, DHI and period. As the offset of this model the logarithm of the number of population exposures in each group was used. We excluded 6 cases because they lacked data for the neighbourhood variable.

All analyses were performed using SPPS v18.0 and the statistical package R (The R Foundation for Statistical Computing, Vienna, Austria), version 3.1.1. Statistical significance was set at $p<0.05$.

\section{Results}

A total of 1791 cases of pertussis were included, of which $6.3 \%$ were diagnosed between 2000 and 2004, 16.0\% between 2005 and 2010, and 77.8\% between 2011 and 2015 . There was $87.7 \%$ of cases classified as confirmed cases. Globally, $41 \%$ of cases were confirmed by diagnostic tests, $13.9 \%$ by epidemiological contact, and $45.2 \%$ using both methods. The remaining $12.3 \%$ of cases were classified as suspected cases. $55.9 \%$ of the cases were female, $84.9 \%$ were natives, and we observed an increase in the average age of cases during the study period. Most cases were from low-average and low DHI neighbourhoods. We also observed an increase in the detection of associated cases 
in the 2011-2015 period, as well as in the number of contact studies performed (Table 1).

The following clinical symptoms were observed in cases: coughing that lasted longer than two weeks (77.8\%), paroxysmal coughing (61.3\%), inspiratory stridor (27.2\%), post-coughing vomiting (29.5\%), apnoea (9.5\%), fever (5.9\%), pneumonia (0.9\%), and convulsions $(0.1 \%)$. There were three deaths during the study period, one in 2008 and two in 2012.

In most cases, hospital admission involved children under 1 year $(252 / 274,92.0 \%)$, and there was a general decrease over time in the percentage of cases under 1 year of age who were admitted to hospital (Table 1).

Vaccination coverage remained high, although we found that the proportion of cases with unknown vaccination status increased during the 2011-2015 period, a period in which cases were also found to be generally older. More than $90 \%$ of children under 6 years $(N=$ 791) were vaccinated, $88.9 \%$ were properly vaccinated according to their age, and $5.7 \%$ were non-vaccinated. Note that parents who are against vaccines only accounted for $3.9 \%$ of all cases in children under 6 years, and $68.9 \%$ of cases involving non-vaccinated children. Vaccination coverage before (91.3\%) and during (90.6\%) the economic recession remained very similar $(p=$ 0.757). Analysing vaccination percentage according to DHI, we found that richer neighbourhoods (very high DHI) included a higher percentage of non-vaccinated cases, as well as a higher percentage of non-vaccinated children under 6 years and under 1 year $(p<0.05)$. Similarly, among vaccinated cases, the highest percentage of incorrect vaccination was observed in very high DHI neighbourhoods in children under 6 years, and in high DHI neighbourhoods in children under 1 year (Table 2).

In the whole-cell vaccine period (2000-2004), $88.0 \%$ of cases under 1 year were vaccinated versus the $95.5 \%$ of cases under 1 year vaccinated in the acellular vaccine period (2005-2015) ( $p=0.01)$. 82.2\% of these were properly vaccinated according to their age between 2000 and 2004 , and $94.6 \%$ in the $2005-2015$ period $(p<0.001)$.

We observed a sustained increase $\left(R^{2}=0.748\right.$ see exponential curve, Fig. 1a) in the incidence of pertussis in Barcelona 2011 onwards, from 3.1 cases/100,000 residents in 2000 to $16.2 / 100,000$ in 2011 , and, following a brief decline, a rise to 37.0 cases/100,000 in 2015. This trend was similar in both males and females (Fig. 1a).

In terms of age, the highest incidence observed during the study period was among children under 1 year old. The incidence remained very low in the rest of the population until 2011, after which we observed an increase among 1to 14-year-olds that persisted until 2015 (Fig. 1b).

Grouping cases according to DHI, we did not observe a stable distribution during years of low incidence, although the incidence was generally higher in poorer neighbourhoods. From 2011 onwards, incidence increased in all neighbourhoods, and remained higher in those with lower DHI (Fig. 1c).

In terms of country of origin, we found that the incidence in children under 15 years old was higher among natives than among foreign-born (PRR $=0.43 \mathrm{CI}$ : 0.32 0.58) (Fig. 1d).

Multivariate analysis showed that the increased incidence observed between 2000 and 2015 was associated with being female ( $\mathrm{aOR}=1.12$, CI:1.02-1.23) and being a case during the 2011-2015 period $(\mathrm{aOR}=1.75$, CI:1.54-2.00). We also observed trend related to age-group, with the strongest association among children less than 1 year old ( $\mathrm{aOR}=27.18, \mathrm{CI}: 23.51-31.44)$. In terms of socio-economic status, we did not observe marked differences between neighbourhoods, although there was a general tendency (Table 3).

\section{Discussion}

In this study we have described evolution of pertussis in Barcelona city between 2000 and 2015. We observed a steady increase in incidence since 2010, which is in line with the trends observed elsewhere in Spain and in other European countries [1,7]. The trend in pertussis incidence in recent decades follows a U-shaped curve, both in Spain and in other countries, such as the US and the UK. This is a similar pattern to that described for other communicable diseases, and requires greater focus on this disease and its control $[6,7,9,16]$. Despite the periodicity of the disease we can see in other studies that the last epidemic wave of pertussis shows an increasing trend of the disease $[6,14,17]$.

This increase does not seem to be related either to limitations in healthcare assistance (healthcare for communicable diseases was maintained in Barcelona, despite the economic recession and Royal Decree 16/12 which hinders access to the healthcare card among immigrants [18]) or to vaccination issues (vaccination coverage in Barcelona remained high over the years). The global rise in cases with unknown vaccination status was due to an increase in the age of cases; such a rise is not observed in the under 6 years and under 1 year age groups. Although the action of the anti-vaccination movement have been associated with a higher disease risk, this remains a minority group in Barcelona [19]. Several Spanish studies have shown the need for new vaccination strategies and more effective vaccines, given that a high percentage of cases is properly vaccinated $[6,14,20]$. Globally, several authors have suggested that vaccination strategies should be reformulated, as a result of their limited efficacy $[5,7,21]$.

The percentage of cases under 1 year of age who received the vaccine was lower in 2000-2004 (when the whole-cell vaccine was used) than in 2005-2015 (in 
Table 1 Distribution of pertussis cases according to epidemiological variables

\begin{tabular}{|c|c|c|c|c|}
\hline & 2000-2004 N (\%) & 2005-2010 N (\%) & $2011-2015$ N (\%) & Total N (\%) \\
\hline All & $112(6.3)$ & $286(16.0)$ & 1393 (77.8) & $1791(100.0)$ \\
\hline Confirmed & 97 (86.6) & $220(76.9)$ & 1253 (89.9) & $1570(87.7)$ \\
\hline Suspected & $15(13.4)$ & $66(23.1)$ & $140(10.1)$ & $221(12.3)$ \\
\hline \multicolumn{5}{|l|}{ Gender } \\
\hline Female & $69(61.6)$ & $160(55.9)$ & $772(55.4)$ & $1001(55.9)$ \\
\hline Male & $43(38.4)$ & $124(43.4)$ & $621(44.6)$ & $788(44.0)$ \\
\hline \multicolumn{5}{|l|}{ Age group } \\
\hline$<1$ year & $83(74.1)$ & $128(45.1)$ & $221(15.9)$ & $432(24.1)$ \\
\hline $1-14$ years & $20(17.9)$ & 89 (31.3) & $782(56.1)$ & 891 (49.7) \\
\hline $15-29$ years & $6(5.4)$ & $22(7.7)$ & $63(4.5)$ & $91(5.1)$ \\
\hline$>30$ years & $3(2.7)$ & $45(15.8)$ & 327 (23.5) & 375 (20.9) \\
\hline \multicolumn{5}{|l|}{ Country of origin } \\
\hline Native & $83(74.1)$ & $220(76.9)$ & $1217(87.4)$ & $1520(84.9)$ \\
\hline Foreign-born & $7(6.3)$ & $26(9.1)$ & $122(8.8)$ & $155(8.7)$ \\
\hline Unknown & $22(19.6)$ & $40(14.0)$ & $54(3.9)$ & $116(6.5)$ \\
\hline \multicolumn{5}{|c|}{ Index of Disposable Household Income (DHI) } \\
\hline Very high & $4(3.6)$ & $15(5.2)$ & $77(5.5)$ & $96(5.4)$ \\
\hline High & $4(3.6)$ & $18(6.3)$ & $77(5.5)$ & $99(5.5)$ \\
\hline Average & $19(17.0)$ & $58(20.3)$ & $325(23.3)$ & $402(22.4)$ \\
\hline Low-average & $41(36.6)$ & $90(31.5)$ & $498(35.8)$ & $629(35.1)$ \\
\hline Low & $41(36.6)$ & $105(36.7)$ & $413(29.6)$ & $559(31.2)$ \\
\hline Unknown & $3(2.7)$ & $0(0.0)$ & $3(0.2)$ & $6(0.3)$ \\
\hline \multicolumn{5}{|l|}{ Case type } \\
\hline Associated & $18(16.1)$ & $127(44.4)$ & $824(59.2)$ & $969(54.1)$ \\
\hline Sporadic & $94(83.9)$ & $159(55.6)$ & $569(40.8)$ & $822(45.9)$ \\
\hline \multicolumn{5}{|l|}{ Contact tracing } \\
\hline Yes & $36(32.1)$ & $216(75.5)$ & $1130(81.1)$ & $1382(77.2)$ \\
\hline No & $76(67.9)$ & $70(24.5)$ & $263(18.9)$ & $409(22.8)$ \\
\hline \multicolumn{5}{|l|}{ Vaccination } \\
\hline Yes & $92(82.1)$ & $236(82.5)$ & $1005(72.1)$ & $1333(74.4)$ \\
\hline No & $8(7.1)$ & $25(8.7)$ & $97(7.0)$ & $130(7.3)$ \\
\hline Unknown & $12(10.7)$ & $25(8.7)$ & $291(20.9)$ & $328(18.3)$ \\
\hline \multicolumn{5}{|c|}{ Hospital admission in $<1$ year $(N=432)$} \\
\hline Yes & $64(77.1)$ & $83(64.8)$ & $105(47.5)$ & $252(58.3)$ \\
\hline No & $19(22.9)$ & $45(35.2)$ & $116(52.5)$ & $180(41.7)$ \\
\hline
\end{tabular}

Barcelona, 2000-2015

which the acellular vaccine was used). Moreover, the latter period was characterised by a higher proportion of properly vaccinated cases. These results agree with the hypothesis of lower efficacy of the acellular vaccine than the whole-cell vaccine $[7,22,23]$.

Apart from the lower efficacy of the acellular vaccine, the increased incidence could be due to a genetic change in the bacteria. Bacterial antigens are known to change over time, and they no longer coincide with the antigenic profile of currently vaccines [24]. The increased incidence could also be due to faster, more sensitive diagnostic tests, improved epidemiological surveillance, better registry systems, and greater awareness by healthcare professionals $[3,7]$. However, US- and UK-based study suggests that asymptomatic transmission could be key for the re-emergence of pertussis [25]. Moreover, pertussis often goes unrecognized among patients. The lack of characteristic symptoms is more common in adults, as opposed to 
Table 2 Vaccination status in pertussis cases according to age group and disposable household income. Barcelona, 2000-2015

\begin{tabular}{|c|c|c|c|c|c|}
\hline & Age group & Vaccinated N (\%) & Non-vaccinated N (\%) & $\begin{array}{l}\text { Unknown vaccination } \\
\text { status N (\%) }\end{array}$ & $\begin{array}{l}\text { Proper vaccination in } \\
\text { vaccinated cases N (\%) }\end{array}$ \\
\hline \multirow[t]{3}{*}{ All categories $(N=1791)$} & Overall & $1333(74.4)$ & $130(7.3)$ & $328(18.3)$ & $1146(86.2)$ \\
\hline & $<6$ years & $718(90.8)$ & $45(5.7)$ & $28(3.5)$ & $635(88.9)$ \\
\hline & $<1$ year & $406(94.0)$ & $15(3.5)$ & $11(2.5)$ & $371(92.3)$ \\
\hline \multirow[t]{3}{*}{ Very high $\mathrm{DHI}(\mathrm{N}=96)$} & Overall & $65(67.7)$ & $12(12.5)$ & 19 (19.8) & $52(80.0)$ \\
\hline & $<6$ years & $37(78.7)$ & $8(17.0)$ & $2(4.3)$ & $31(83.8)$ \\
\hline & $<1$ year & $16(76.2)$ & $4(19.1)$ & $1(4.8)$ & $15(93.8)$ \\
\hline \multirow[t]{3}{*}{ High DHI $(N=99)$} & Overall & $73(73.7)$ & $11(11.1)$ & $15(15.2)$ & $60(82.2)$ \\
\hline & $<6$ years & $36(85.7)$ & $4(9.5)$ & $2(4.8)$ & $32(88.9)$ \\
\hline & $<1$ year & $18(94.7)$ & $0(0.0)$ & $1(5.3)$ & $15(83.3)$ \\
\hline \multirow[t]{3}{*}{ Average DHI $(N=402)$} & Overall & $280(69.7)$ & $29(7.2)$ & $93(23.1)$ & $239(85.4)$ \\
\hline & $<6$ years & $148(88.6)$ & $9(5.4)$ & $10(6.0)$ & $127(85.8)$ \\
\hline & $<1$ year & $95(94.1)$ & $3(3.0)$ & $3(3.0)$ & 87 (91.6) \\
\hline \multirow[t]{3}{*}{ Average-low DHI (N = 629) } & Overall & $464(73.8)$ & $42(6.7)$ & $123(19.6)$ & $401(86.4)$ \\
\hline & $<6$ years & $236(91.1)$ & $15(5.8)$ & $8(3.1)$ & $212(89.8)$ \\
\hline & $<1$ year & $120(94.5)$ & $5(3.9)$ & $2(1.6)$ & 109 (90.8) \\
\hline \multirow[t]{3}{*}{ Low DHI $(N=559)$} & Overall & $447(80.0)$ & $36(6.4)$ & 76 (13.6) & $394(88.1)$ \\
\hline & $<6$ years & $257(95.2)$ & $9(3.3)$ & $4(1.5)$ & $233(90.7)$ \\
\hline & $<1$ year & $153(96.8)$ & $3(1.9)$ & $2(1.3)$ & $145(94.8)$ \\
\hline
\end{tabular}

children. In this sense, a review of studies from several countries showed the high seroprevalence of $B$. pertussis compared to the number of diseases that were notified [26]. This findings emphasise the need for better and maintained epidemiological surveillance in the entire population.

While children under 1 year are the most vulnerable age group, and the group with the highest disease incidence, we observed an increase among children older than 1 year and among teenagers. This increase in the age of cases may be due to greater awareness among healthcare professionals, leading to increased diagnosis among teenagers and adults (symptoms are less severe in these groups and thus harder to identify). The absence of characteristic symptoms results in greater diagnosis delay, such that other individuals are exposed to infected individuals for longer. This increase in age could also be due to reduced acquired immunity over time, which is attributed to the change in vaccine from whole-cell to an acellular vaccine and to reduced natural immunity after several years of low disease incidence, which does not allow immunity to be strengthened through naturally occurring disease $[3,6,22,23,27,28]$. This decrease in immunity may have caused increased transmission between older children, teenagers and adults, who would in turn transmit the disease to younger children $[2,29,30]$. Other studies have also described increased reporting of cases at older ages, despite correct vaccination coverage [4, 9, 31-33]. This change highlights a need for a booster dose in vaccination schedules during teenage years.

The decline in the number of cases under 1 year of age who were admitted to hospital could be because formerly only the most severe cases were notified, because of improved hospital admission criteria, or because the disease appears in less severe forms that do not require hospitalization. This could also be related to earlier more precise diagnoses, and the use of faster, more sensitive diagnostic techniques.

Moreover, native children aged 0-14 years show higher disease incidence than among foreign-born children, in spite of the economic recession. This could be because low-income countries still use the whole-cell vaccine, which provides a longer-lasting immunity. In addition, immigrant children from countries with a high incidence of pertussis would have higher natural immunity.

Examining neighbourhoods according to DHI, we found that those with very high DHI had a lower incidence of pertussis. However, although these neighbourhoods have fewer cases, they show a higher percentage of non-vaccinated and not correctly vaccinated cases. Thus, some cases of infection may have occurred because of improper vaccination. As for all communicable disease, most cases of pertussis cluster in disadvantaged neighbourhoods in large cities, where poorer living conditions such as poor hygiene or overcrowding in small apartments 


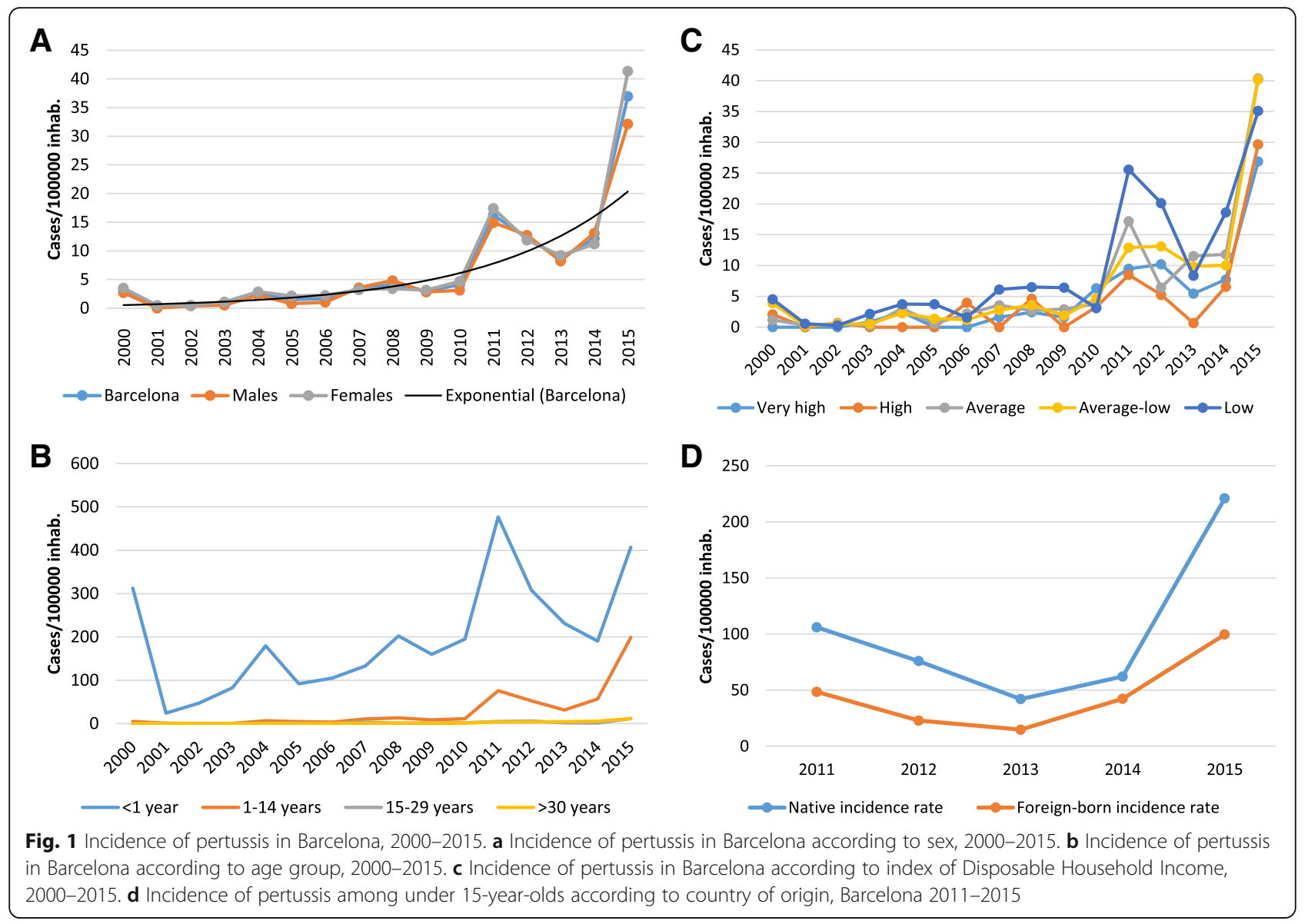

Table 3 Analysis of factors associated with pertussis incidence in Barcelona, 2000-2015

\begin{tabular}{llllll}
\hline Variables & Categories & COR & $95 \% \mathrm{Cl}$ & $\mathrm{aOR}$ & $95 \% \mathrm{Cl}$ \\
\hline Gender & Male & 1 & & 1 & \\
& Female & 0.87 & $0.80-0.96$ & 1.12 & $1.02-1.23$ \\
Age group & $<1$ year & 23.13 & $20.13-26.57$ & 27.18 & $23.51-31.44$ \\
& 1-14 years & 6.64 & $5.89-7.50$ & 6.80 & $6.03-7.69$ \\
& 15-29years & 1.70 & $1.34-2.12$ & 1.76 & $1.39-2.20$ \\
& $>$ 30years & 1 & & 1 & \\
DHI & V.high-high & 1 & & 1 & \\
& Average & 1.21 & $1.02-1.44$ & 1.31 & $1.10-1.55$ \\
& Average-low & 1.63 & $1.39-1.91$ & 1.64 & $1.40-1.94$ \\
& Low & 1.71 & $1.46-2.02$ & 1.62 & $1.37-1.91$ \\
Period & 2000-2004 & 2.23 & $1.78-2.77$ & 1.11 & $0.88-1.38$ \\
& 2005-2010 & 1 & & 1 & \\
& 2011-2015 & 1.24 & $1.09-1.41$ & 1.75 & $1.54-2.00$ \\
\hline
\end{tabular}

Adjusted for the variables gender, age group, $\mathrm{DHI}$ and period $D H I$ disposable household income, $c O R$ crude odds ratio, $a O R$ adjusted odds ratio, $\mathrm{Cl}$ confidence interval leads to increased disease transmission [34-36]. However, note that health-related actions should not be limited to these neighbourhoods, as multivariate analysis shows that all neighbourhoods in the city are at risk of a similar increase in incidence. This shows that, despite the economic recession, neighbourhoods with low DHI have not been disproportionately affected.

Our multivariate analysis showed a remarkable association between the pertussis and children under 1 year of age. Thus, this age group should be the focus of resources and future health-related actions, and it would be also be necessary to promote vaccination in pregnant women.

Although economic recessions have previously been linked to negative impacts on child health [37], the current recession does not seem to have affected access to the healthcare system or vaccination coverage, and foreign-born children were not more seriously afflicted than native children. Thus, the increase detected is due to other factors mentioned above, such as vaccine effectiveness, reduced immunity, gene changes in B. pertussis, and the availability of new diagnostic tests.

A possible limitation of the study is under-diagnosis and under-notification of the disease, mostly in adult population, as well as the absence of data on their vaccination 
status. Nonetheless, this is a population-based study of Barcelona city that includes 16 years of data from the BPHA registry. In addition, socio-economic level was determined using a DHI indicator created by Barcelona City Council. Given the high number of cases and their follow-up, we consider this to be a valid study of considerable scientific interest.

\section{Conclusions}

The noteworthy increase in pertussis incidence does not seem to be due to the economic recession, but to other factors such as vaccine effectivity or genetic change in the bacteria. The increased incidence could also be due to faster, more sensitive diagnostic tests, improved epidemiological surveillance, better registry systems and greater awareness by healthcare professionals. Another key factor could be asymptomatic transmission and the absence of characteristic symptoms among infected people. Although we observed an increase in the age of cases, children under 1 year continue to be the most vulnerable age group, and the group with the highest disease incidence. According to the index of DHI, we observed that neighbourhoods with low DHI have not been disproportionately affected. However, pertussis incidence increased from 2011 onwards in all neighbourhoods and remained higher in those with lower DHI.

In conclusion, we consider that the following measures should be undertaken to improve the epidemiology of the disease: (i) prioritize preventive measures to prevent transmission to most vulnerable groups including children under 1 year such as vaccinate pregnant women; (ii) intensify epidemiological surveillance in the entire population.

\footnotetext{
Abbreviations

aOR: adjusted odds ratio; BPHA: Barcelona Public Health Agency; Cl: confidence intervals; COR: crude odds ratio; DHI: disposable household income; ECDC: European Centre for Disease Prevention and Control; EU: European Union; GLM: generalized linear model; ND: Notifiable Disease; OR: odds ratio; PCR: Polymerase Chain Reaction; PRR: Incidence proportion rate ratio; UK: United Kingdom; US: United States
}

\footnotetext{
Acknowledgements

The authors would like to thank all the public health nurses of BPHA for their support and contributions to this study. This study would not have been possible without the participation of the committed team from the BPHA. We would also like to extend our thanks to the Barcelona Pertussis Working Group for his participation and assistance in this project. We are very grateful for the reporting of pertussis cases done in the years 2000 to 2015 by the health care centres and hospitals of Barcelona. Finally, we also would like to thank to Tomas Perez-Porcuna, Andrea Martin, Toni Soriano and Antoni Noguera for their contributions in the discussion of the results.

Barcelona Pertussis Working Group: Pere Simón, Anna de Andrés, Roser Clos, Montse Ricart, Miriam Ros, Maria José Santomà, Pilar Gorrindo, Pilar Palau, Montse Cunillé, Eva Masdeu, Ingrid Avellanés (Agència de Salut Pública de Barcelona, Barcelona, Spain), Jose Ángel Rodrigo, Gema Codina, Maria Teresa Martin, Juan José González (Hospital Universitari Vall Hebrón, Barcelona, Spain), Sònia Brió (Hospital de la Santa Creu i Sant Pau, Barcelona, Spain), Jessica Del Carpio, Andrea Otero (Hospital Universitari Dexeus, Barcelona, Spain), Álvaro Díaz (Hospital de Nens de Barcelona, Barcelona, Spain), Núria López (Hospital del Mar, Barcelona, Spain), Montse Vaqué, Pere Sala, Marta Calsina, Yolanda Meije (Hospital de Barcelona, Barcelona, Spain), Eulàlia
}

Guasch, Maria Rosa Pascual (Centre d'Atenció Primària Via Barcino, Barcelona, Spain), Carme Palasi (Centre d'Atenció Primària Sardenya, Barcelona, Spain), Anna Luz Moro (Centre d'Atenció Primària Larrard, Barcelona, Spain), Manel Enrubia (Centre d'Atenció Pediàtrica Integral Barcelona Esquerra, Barcelona, Spain), Gemma Monsó (Centre d'Atenció Primària Rio de Janeiro, Barcelona, Spain), Joan Martí Solé (Centre d'Atenció Primària Sant Andreu, Barcelona, Spain), Paloma Rodríguez, Helena Pallarès, Antoni Salvà (Consorci d'Atenció Primària de Salut Barcelona Esquerra, Barcelona, Spain), Ángeles Ferrández (Centre d'Atenció Primària Ciutat Meridiana, Barcelona, Spain), Ana María Hostalot (Centre d'Atenció Primària Pare Claret, Barcelona, Spain), María Carmen Muñoz (Hospital Sant Joan de Déu, Barcelona, Spain). Corresponding autor: Anna de Andrés; aandres@aspb.cat

\section{Ethical approval and consent to participate}

All data were treated and analysed according to the ethical guidelines for human experimentation defined in the Declaration of Helsinki (1964) and reviewed by the World Health Organization in Fortaleza (Brazil) in 2013 [38]. Data and registers were made anonymous to guarantee their confidentiality. The study complies with Spanish Organic Law on Personal Data Protection (15/1999) [39].

This study was evaluated and approved by the Clinical Research Ethics Committee of Parc de Salut Mar (CEIC - Parc Salut Mar, project 2013/5246/I). Consent to participate was not applicable for this study.

\section{Funding}

No additional funding was required for the preparation of this article.

\section{Availability of data and materials}

The datasets generated and/or analysed during the current study are not publicly available due to the data belong to the Barcelona Public Health Agency that is a public institution where data of residents of Barcelona are collected and kept. According to the data protection law and the regulations of the entity, data can not be disseminated or shared but are available from the corresponding author on reasonable request.

\section{Authors' contributions}

SB participated in the design and development of the study, carried out the data analysis and interpretation, and drafted the manuscript. JPM formulated the idea, participated in the design of the study and supervised the analysis and interpretation of the results, and the drafting of the manuscript. CR participated in the study design and supervised the development of the study, the analysis and the drafting of the manuscript. MC performed the statistical analyses and interpretation and commented on the manuscript. JAC participated in the idea and design, data analysis and interpretation, and critically revised the manuscript. The Barcelona Pertussis Working Group participated in the acquisition of data through the diagnostic, treatment, follow up and notification of the pertussis cases, entered the data in the database, revised the content of the manuscript critically and supervised and approved the draft of the manuscript. All authors read and approved the final manuscript.

Consent for publication

Not applicable.

\section{Competing interests}

The authors declare that they have no competing interests.

\section{Publisher's Note}

Springer Nature remains neutral with regard to jurisdictional claims in published maps and institutional affiliations.

\author{
Author details \\ ${ }^{1}$ Servei d'epidemiologia, Agència de Salut Pública de Barcelona, Barcelona, \\ Spain. ${ }^{2}$ Centro de Investigación Biomédica en Red de Epidemiología y Salud \\ Pública (CIBERESP), Barcelona, Spain. ${ }^{3}$ Departamento de Pediatría, Obstetricia \\ y Ginecología y Medicina Preventiva, Facultad de Medicina, Universidad \\ Autónoma de Barcelona, Barcelona, Spain. ${ }^{4}$ Tuberculosis Research Unit \\ Foundation (fuiTB), Barcelona, Spain. ${ }^{5}$ Sport and Physical Activity Studies \\ Centre (CEEAF), University of Vic-Central University of Catalonia (UVic-UCC), \\ Barcelona, Spain.
}


Received: 1 February 2018 Accepted: 17 January 2019

Published online: 04 February 2019

\section{References}

1. European Centre for Disease Prevention and Control. Annual epidemiological report 2014 - vaccine-preventable diseases. Stockholm: ECDC; 2014

2. Wendelboe AM, Njamkepo E, Bourillon A, Floret DD, Gaudelus J, Gerber M, et al. Transmission of Bordetella pertussis to young infants. Pediatr Infect Dis J. 2007;26(4):293-9.

3. Tan T, Dalby T, Forsyth K, Halperin SA, Heininger U, Hozbor D, et al. Pertussis across the globe: recent epidemiologic trends from 2000 to 2013. Pediatr Infect Dis J. 2015;34(9):e222-32.

4. Heininger U, André P, Chlibek R, Kristufkova Z, Kutsar K, Mangarov A, et al. Comparative epidemiologic characteristics of pertussis in 10 central and eastern European countries, 2000-2013. PLoS One. 2016;11(6):e0155949.

5. Sabbe $M$, Vandermeulen $C$. The resurgence of mumps and pertussis. Hum Vaccin Immunother. 2016;12(4):955-9.

6. Sizaire V, Garrido-Estepa M, Masa-Calles J, Martinez de Aragon MV. Increase of pertussis incidence in 2010 to 2012 after 12 years of low circulation in Spain. Euro Surveill. 2014;19(32)

7. Sealey KL, Belcher T, Preston A. Bordetella pertussis epidemiology and evolution in the light of pertussis resurgence. Infect Genet Evol. 2016;40:136-43.

8. Domenech de Cellès M, Magpantay FM, King AA, Rohani P. The pertussis enigma: reconciling epidemiology, immunology and evolution. Proc Biol Sci. 2016;283(1822).

9. Clark TA. Changing pertussis epidemiology: everything old is new again. $J$ Infect Dis. 2014;209:978-81.

10. Rechel B, Suhrcke M, Tsolova S, Suk JE, Desai M, McKee M, et al. Economic crisis and communicable disease control in Europe: a scoping study among national experts. Health Policy [Internet]. Elsevier Ireland Ltd; 2011 Dec [cited 2017 January 23]:103(2-3):168-75. Available from: http://www.ncbi. nlm.nih.gov/pubmed/21820196.

11. Suhrcke M, Stuckler D, Suk JE, Desai M, Senek M, McKee M, et al. The impact of economic crises on communicable disease transmission and control: a systematic review of the evidence. PLoS One [Internet]. 2011 Jan [cited ];6(6):e20724.

12. Ajuntament de Barcelona. Departament d'Estadística. Available at: http:// www.bcn.cat/estadistica/angles/index.htm

13. Generalitat de Catalunya. Departament de Salut. Definició de cas de les malalties de declaració obligatòria. 11a ed. Barcelona: Generalitat de Catalunya; 2006. Available at: https://scientiasalut.gencat.cat/bitstream/ handle/11351/1089/definicio_malalties_declaracio_obligatoria_2010. pdf?sequence $=1$

14. Moraga-Llop FA, Campins-Martí M. Vacuna de la tos ferina. Reemergencia de la enfermedad y nuevas estrategias de vacunación. Enferm Infecc Microbiol Clin. 2015;33(3):190-6.

15. Marti C, Casas E, Jorge Juan A, Martí J, Conde J, Figuerola G, et al. Distribució territorial de la Renda Familiar per càpita a Barcelona. Ajuntament de Barcelona; 2007. Available at: http://www.bcn.cat/ publicacions/pdf/rfd.pdf (accessed 14 Oct 2016).

16. Reichman LB. The U-shaped curve of concern. Am Rev Respir Dis. 1991; 144(4):741-2.

17. Broutin H, Guégan JF, Elguero E, Simondon F, Cazelles B. Large-scale comparative analysis of pertussis population dynamics: periodicity, synchrony, and impact of vaccination. Am J Epidemiol. 2005 Jun 15;161(12): 1159-67.

18. Real Decreto-ley 16/2012, de 20 de abril, de medidas urgentes para garantizar la sostenibilidad del Sistema Nacional de Salud y mejorar la calidad y seguridad de sus prestaciones. (Boletín Oficial del Estado, número 98, de 24 de abril de 2012).

19. Salmon DA, Dudley MZ, Glanz JM, Omer SB. Vaccine Hesitancy. Causes, Consequences, and a Call to Action. Am J Prev Med. 2015;49(654):S391-8.

20. Moraga-Llop FA, Mendoza N, Muntaner A, Codina G, Fàbregas A, Campins M. Pertussis in fully vaccinated infants and children. Are new vaccination strategies required? Enferm Infecc Microbiol Clin. 2014:32(4):236-41.

21. Bolotin S, Harvill ET, Crowcroft NS. What to do about pertussis vaccines? Linking what we know about pertussis vaccine effectiveness, immunology and disease transmission to create a better vaccine. Pathog Dis. 2015;73(8).
22. Sheridan SL, Ware RS, Grimwood K, Lambert SB. Reduced risk of pertussis in whole-cell compared to acellular vaccine recipients is not confounded by age or receipt of booster-doses. Vaccine. 2015;33(39):5027-30.

23. Fulton TR, Phadke VK, Orenstein WA, Hinman AR, Johnson WD, Omer SB. Protective effect of contemporary pertussis vaccines: a systematic review and meta-analysis. Clin Infect Dis. 2016;62(9):1100-10.

24. van Gent M, Heuvelman CJ, van der Heide HG, Hallander HO, Advani A, Guiso N, et al. Analysis of Bordetella pertussis clinical isolates circulating in European countries during the period 1998-2012. Eur J Clin Microbiol Infect Dis. 2015;34(4):821-30.

25. Althouse BM, Scarpino SV. Asymptomatic transmission and the resurgence of Bordetella pertussis. BMC Med. 2015;13:146

26. Barkoff AM, Gröndahl-Yli-Hannuksela K, He Q. Seroprevalence studies of pertussis: what have we learned from different immunized populations. Pathog Dis. 2015;73(7)

27. Schwartz KL, Kwong JC, Deeks SL, Campitelli MA, Jamieson FB, MarchandAustin $A$, et al. Effectiveness of pertussis vaccination and duration of immunity. CMAJ. 2016;188(16):E399-406.

28. Klein NP, Bartlett J, Rowhani-Rahbar A, Fireman B, Baxter R. Waning protection after fifth dose of acellular pertussis vaccine in children. $N$ Engl J Med. 2012;367(11):1012-9.

29. de Greeff SC, Mooi FR, Westerhof A, Verbakel JMM, Peeters MF, Heuvelman CJ, et al. Pertussis disease burden in the household: how to protect young infants. Clin Infect Dis. 2010;50:1339-45.

30. van der Maas NA, Mooi FR, de Greeff SC, Berbers GA, Spaendonck MA, de Melker HE. Pertussis in the Netherlands, is the current vaccination strategy sufficient to reduce disease burden in young infants? Vaccine. 2013;31(41): 4541-7.

31. Crespo I, Cardeñosa N, Godoy P, Carmona G, Sala MR, Barrabeig I, et al. Epidemiology of pertussis in a country with high vaccination coverage. Vaccine. 2011;29:4244-8.

32. Hellenbrand W, Beier D, Jensen E, Littmann M, Meyer C, Oppermann H, et al. The epidemiology of pertussis in Germany: past and present. BMC Infect Dis. 2009;9:22.

33. de Greeff SC, de Melker HE, van Gageldonk PGM, Schellekens JFP, van der Klis FRM, Mollema L, et al. Seroprevalence of pertussis in the Netherlands: evidence for increased circulation of Bordetella pertussis. PLoS One. 2010;5: e14183.

34. Suhrcke M, Stuckler D, Suk JE, Desai M, Senek M, McKee M, et al. The impact of economic crises on communicable disease transmission and control: a systematic review of the evidence. PLoS One. 2011;6(6):e20724.

35. Levri KM, Reynolds L, Liko J, Dott M, Robinson BF, Cieslak PR. Risk factors for pertussis among Hispanic infants: metropolitan Portland, Oregon, 20102012. Pediatr Infect Dis J. 2016:35(5):488-93.

36. Zamir CS, Dahan DB, Shoob H. Pertussis in infants under one year old: risk markers and vaccination status--a case-control study. Vaccine. 2015;33(17): 2073-8.

37. Rajmil L, Fernandez de Sanmamed MJ, Choonara I, Faresjö T, Hjern A, Kozyrskyj AL, et al. Impact of the 2008 economic and financial crisis on child health: a systematic review. Int J Environ Res Public Health. 2014;11(6):6528-46.

38. Declaración de Helsinki de la AMM. Principios éticos para las investigaciones médicas en seres humanos. [Internet]. Asociación Médica Mundial; 2013. Available at: http:/www.isciii.es/ISCIII/es/contenidos/fd-investigacion/fdevaluacion/fd-evaluacion-etica-investigacion/Declaracion-Helsinki-2013-Esp.pdf

39. Ley Orgánica 15/1999, de 13 de diciembre, de Protección de Datos de Carácter Personal. [Internet]. Madrid: Noticias jurídicas; 2011. Available at: http://noticias.juridicas.com/base_datos/Admin/lo15-1999.html

Ready to submit your research? Choose BMC and benefit from:

- fast, convenient online submission

- thorough peer review by experienced researchers in your field

- rapid publication on acceptance

- support for research data, including large and complex data types

- gold Open Access which fosters wider collaboration and increased citations

- maximum visibility for your research: over $100 \mathrm{M}$ website views per year

At $\mathrm{BMC}$, research is always in progress.

Learn more biomedcentral.com/submission 